\title{
PENGGUNAAN MULTIMEDIA DALAM PEMBELAJARAN TEORI KINETIK GAS DI SMA/MA NEGERI DAN SWASTA KECAMATAN SAMBAS
}

\author{
Jaka Afriana ${ }^{1)}$, Rio Rikardo ${ }^{1)}$, Burhanuddin ${ }^{1)}$ \\ SMA Santo Bonaventura ${ }^{1)}$
}

\begin{abstract}
Using Multimedia in Learning Kinetic Gas Theory in SMA / MA Public and Private District of Sambas. This study aims to see changes in student learning outcomes after learning using multimedia by comparing the value of the learning outcomes of the pre-test and post-test. Quasi-experimental methods used in this study with one group pretest-posttest design. Research subjects choose three of four SMA/ MA Public and Private District of Sambas which has a program of Natural Sciences, SMA Negeri 1 Sambas (20 students), MAN Sambas (19 students), and SMA Santo Bonaventura (16 students). Based on the data analysis and discussion, the average percentage of learning outcomes pre-test on Gas Kinetic Theory of $53.68 \%$ of the 55 students. While the average percentage of learning outcomes post-test $69.04 \%$ of the 55 students. The increase in the average percentage of student learning outcomes in the material Kinetic Theory of Gases using multimedia for $15.37 \%$. The results of calculations using the McNemar test, of the total ten questions occur to improving student learning outcomes Gas Kinetic Theory of matter between before and after learning using multimedia, which calculate the average $X^{2}$ mean $=9.10$ and $X^{2}$ table mean $=3.84$ this means that the calculated $X_{\text {hitung }}^{2}>X_{\text {table. }}^{2}$.
\end{abstract}

Keywords : Multimedia, kinetic theory of gases.

Penelitian pendidikan pada hakekatnya merupakan penerapan penelitian ilmiah dalam bidang pendidikan. Penelitian dalam bidang pendidikan sangat dibutuhkan untuk kemajuan dan perkembangan ilmu pengetahuan. Kemajuan dan perkembangan ilmu pengetahuan akan meningkatkan mutu pendidikan itu. Sains pada umumnya dan fisika khususnya merupakan salah satu pelajaran yang diajarkan pada setiap jenjang pendidikan formal, karena berkaitan erat dengan kehidupan sehari-hari, baik menyangkut kejadian alam maupun barang-barang hasil teknologi. Akan tetapi, belajar fisika masih dirasakan sulit oleh sebagian besar siswa. Kesulitan belajar fisika yang dirasakan siswa karena banyak mempelajari rumus dan konsep. Rumus dan konsep harus siswa kuasai agar memahami materi dengan baik dan dapat diterapkan dalam kehidupan sehari-hari.

Seorang siswa dalam belajar fisika dikatakan kurang berhasil apabila perolehan hasil belajar yang 
berupa nilai belum mencapai suatu standar yang telah ditetapkan. Untuk mencapai suatu hasil belajar yang maksimal, banyak aspek yang mempengaruhinya, di antaranya aspek guru, siswa, metode pembelajaran dan lain-lain. Salah satu materi dalam pelajaran fisika adalah Teori Kinetika Gas. Hasil belajar siswa sebagian besar belum mencapai nilai Kriteria Ketuntasan Minimal (KKM). Perolehan nilai ulangan kompetensi dasar di SMA Santo Bonaventura ditemukan hanya 12,5\% yang melampaui KKM, sedangkan pada MAN Sambas diperoleh persentase $26,3 \%$. Tentu hasil ini jauh dari yang diharapkan.

Guru sebagai tenaga pendidik profesional diharapkan dapat mengembangkan ilmu pengetahuan yang dimilikinya. Pengetahuan yang bersifat abstrak hendaknya dituangkan dalam suatu bahasa atau pengertian yang mudah dipahami. Dalam teori kinetika gas, siswa merasa sulit membayangkan partikelpartikel gas yang sangat kecil, sehingga perlu dikembangkan media pembelajaran yang menvisualisasikan partikel-partikel gas dalam animasi gerak tiga dimensi. Pada jaman sekarang, fasilitas teknologi informasi (TI) berkembang semakin pesat sehingga penggunaan berbagai instrumen TI dapat diterapkan dalam pembelajaran fisika, misalnya multimedia. Multimedia dapat diartikan sebagai penggunaan beberapa media yang berbeda untuk menggabungkan dan menyampaikan informasi dalam bentuk teks, audio, grafik, animasi, dan video. Multimedia sebagai media pembelajaran yang dikembangkan berupa tampilan animasi dalam bentuk slide show. Media ini juga menampilkan materi fisika yang dikemas dengan animasi visual dan psikomotor sehingga diharapkan dapat membantu siswa memahami konsep yang dipelajari secara nyata.

Penelitian yang dilakukan untuk melihat peningkatan hasil belajar siswa setelah diberikan pengajaran ulang menggunakan multimedia. Penggunaan multimedia didasarkan bahwa "Siswa belajar sesuatu dari orang tua dan orang disekitarnya, terutama mengenai norma dan tingkah laku. Televisi, yang menyajikan pendidikan dalam bentuk hiburan, juga memberikan pengaruh yang besar (Simpson and Anderson, 1981:17) ". Tampilan slide show yang digunakan dapat diibaratkan tampilan layar televisi, dimana siswa diajak menikmati tampilan animasi tanpa meninggalkan pemahaman konsep. Kehadiran multimedia juga dimaksudkan untuk mengurangi kejenuhan siswa dalam belajar, menarik minat siswa, dan jika dikembangkan dapat dimanfaatkan sebagai solusi alternatif dari praktikum.

Masalah dalam penelitian adalah "Bagaimana hasil belajar siswa tentang teori kinetik gas setelah dilakukan pembelajaran dengan menggunakan multimedia?". Penelitian ini bertujuan untuk "melihat perubahan hasil belajar siswa setelah dilakukan pembelajaran menggunakan multimedia dengan membandingkan nilai hasil belajar dari hasil pre-test dan post-test". Manfaat penelitian bagi pendidik adalah sebagai bahan evaluasi dalam penggunaan metode pengajaran alternatif. Bagi siswa, penelitian ini diharapkan dapat memotivasi siswa 
agar bersemangat dalam belajar, dan mengurangi kejenuhan siswa dalam belajar.

Hasil belajar merupakan kemampuan menuangkan semua pengetahuan yang telah dimiliki dari pengalaman belajar. Kemampuan ini akan terlihat ketika pendidik melakukan penilaian melalui tes atau pengalaman langsung dengan menjawab soal-soal. Salah satu tujuan penilaian dilakukan sebagai umpan balik atau alat evaluasi untuk perbaikan pengajaran.Hasil belajar mengisyaratkan adanya penciptaan makna oleh siswa atas materi atau substansi dalam suatu bidang ilmu pengetahuan tertentu. Penciptaan makna dapat berupa kemampuan siswa menerima dan menterjemahkan materi yang diajarkan. Dalam menerima materi, faktor kognitif siswa dan keterampilan guru dalam mengajar dapat menentukan tercapainya tujuan pembelajaran.

Tujuan pembelajaran biasanya ditentukan dengan memberikan standar nilai yang akan dikejar siswa. Standar ini dikenal dengan kriteria ketuntasan minimal (KKM). Siswa dikatakan berhasil dalam mengikuti pelajaran jika nilai yang diperoleh dari hasil tes kompetensi melebihi nilai KKM yang telah ditetapkan. Sebaliknya, jika perolehan nilai dibawah standar guru sebaiknya melakukan evaluasi terhadap kinerja dalam mengajar. Evaluasi terhadap guru dapat ditinjau dari segi metode pembelajaran. Kesesuaian materi dengan metode yang digunakan hendaknya dikemas scmenarik mungkin sehingga dapat menjembatani pemahaman siswa. Guru dapat melakukan pengajaran ulang terhadap materi yang sama untuk memperbaiki kesalahan maupun hasil belajar siswa. Kegiatan ini dikenal dengan program remedial. Akan tetapi, program remedial lebih sering diartikan sebagai pemberian tes ulang.

Menurut Ischak dan Warji (1987:1) kegiatan perbaikan dalam proses belajar mengajar adalah salah satu bentuk pemberian bantuan itu, yaitu suatu pemberian bantuan di dalam proses belajar mengajar yang berupa kegiatan perbaikan yang terprogram dan disusun secara sistematis. Perbaikan belajar sering juga disebut sebagai kegiatan pembelajaran remedial atau pengajaran ulang. Pengajaran remedial dalam proses belajar mengajar merupakan salah satu bentuk kegiatan pemberian bantuan yang berupa perlakuan pengajaran maupun berupa bimbingan kepada siswa yang lambat dan kesulitan dalam memahami konsep agar siswa dapat menguasai bahan pelajaran yang diberikan.

Bentuk pelaksanaan pembelajaran remedial diantaranya: pemberian bimbingan secara khusus, misalnya bimbingan perorangan jika jumlah pesertadidik yang mengikuti remedial maksimal 20\%; pemberian tugas-tugas kelompok jika jumlah peserta yang mengikuti remedial lebih dari $20 \%$ tetapi kurang dari 50\%; pemanfaatan tutor teman sebaya; dan yang umum dilaksanakan berupa pemberian tes ulang. Pemberian pembelajaran ulang dengan metode dan media yang berbeda dilakukan jika jumlah peserta yang mengikuti remedial lebih dari $50 \%$. Pembelajaran remedial dan tes ulang dilaksanakan di luar jam tatap muka. Semua pembelajaran remedial 
diakhiri dengan tes ulang mampu mengolah presentasi (Anonimous. 2011). Multimedia adalah penggunaan komputer untuk menyajikan dan menggabungkan teks, suara, gambar, animasi dan video dengan alat bantu dan koneksi sehingga pengguna dapat mengendalikan sendiri, berinteraksi, berkarya dan berkomunikasi. Dalam dunia pendidikan, multimedia digunakan sebagai media proses belajar mengajar, baik dalam kelas maupun secara sendiri-sendiri. Pada perkembangannya, multimedia dibagi atas dua jenis yaitu "Multimedia Linier" dan "Multimedia Interaktif. Multimedia Liner adalah jenis multimedia yang berjalan lurus. Multimedia jenis ini bisa dilihat pada semua jenis film, dan Tutorial Video. Sedangkan Multimedia Interaktif adalah jenis multimedia interaksi, artinya ada interaksi antara media dengan pengguna media melalui bantuan komputer, dan mouse keyboard.

Menurut wikipedia (2011), powerpoint merupakan salah satu multimedia yang sering digunakan. Penggunaan powerpoint sebagian besar hanya sebatas lembaranlembaran kertas yang berisikan konsep penting namun terlihat kaku, dan pengganti tulisan di papan tulis. Dalam powerpoint, seperti halnya perangkat lunak pengolah presentasi lainnya, objek teks, grafik, video, suara, dan objek-objek lainnya dapat diposisikan dalam beberapa halaman individual yang disebut dengan slide. Istilah slide dalam Powerpoint ini memiliki analogi yang sama dengan slide dalam proyektor biasa, yang telah kuno, akibat munculnya perangkat lunak komputer yang

semacam powerpoint dan impress. Setiap slide dapat dicetak atau ditampilkan dalam layar dan dapat dinavigasikan melalui perintah yang akan dilakukan.

Penggunaan multimedia yang dimaksudkan disini adalah pengembangan powerpoint dengan melibatkan unsur animasi dalam efek visual. Sehingga dapat memberikan tontonan ilmu pengetahuan yang bersifat abstrak kedalam tampilan yang mudah dipahami. Materi teori kinetik gas yang diajarkan meliputi sifat gas ideal, hukum-hukum gas, persamaan gas ideal, dan teorema ekipartisi energi. Gas ideal didefinisikan dengan suatu asumsi (anggapan) tetapi tetap konsisten dengan definisi makroskopis. Sifatsifat mikroskopis gas seperti tekanan, volum, dan temperatur cenderung memperlihatkan hubungan sederhana pada temperatur tinggi dan rendah (Supiyanto, 2003 :104).

Sebagian besar siswa merasa kesulitan, bagaimana cara mendefininisikan, mengidentifikasi dan membuktikan konsep terutama pada materi Teori Kinetik Gas. Pencapaian hasil belajar siswa pada materi tersebut, dalam 2 tahun terakhircenderung hasilnya kurang optimal, siswa yang mencapai ketuntasan kurang dari $50 \%$.

\section{Metode}

Metode penelitian yang digunakan pada penelitian ini adalah metode eksperimen semu(Quasy Experiment).Menurut Suryabrata (2005), tujuan penelitian eksperimen semu adalah untuk memperoleh informasi yang didapat dengan eksperimen yang sebenarnya dalam 
keadaan yang tidak memungkinkan untuk mengontrol dan/atau memanipulasikan semua variabel yang relevan. Penelitian ini bertujuan untuk meningkatkan hasil belajar siswa menggunakan multimedia setelah diberikan perlakuan kepada satu kelompok siswa. Rancangan One Group Pretest-Posttest Designdigunakan dalam penelitian ini. Menurut Suryabrata (2005), dalam rancangan ini digunakan satu kelompok subjek. Langkah pertama melakukan pengukuran lalu dikenakan perlakuan, yaitu kegiatan pembelajaran dan diakhiri dengan pengukuran untuk kedua kalinya.

Penelitian ini memilih tiga dari empat SMA/MA Kecamatan Sambas yang memiliki program Ilmu Alam, yaitu SMA Negeri 1 sambas, MAN Sambas, dan SMA Santo Bonaventura Sambas. Populasi dalam penelitian ini adalah seluruh siswa kelas XI Program Ilmu Alam SMA Negeri 1 Sambas, MAN Sambas, dan SMA Santo Bonaventura Sambas. Pengambilan sampel diambil secara utuh pada MAN Sambas berjumlah 19 siswa, dan SMA Bonaventura Sambas sebanyak 16 siswa, sedangkan pada SMA Negeri 1 Sambas sampel diambil secara acak dipilih 20 siswa dari 60 siswa secara keseluruhan. Jadi sampel pada penelitian iniberjumlah 55 siswa.

$$
\text { Instrumen penelitian ini }
$$

berupa tes pilihan ganda sebanyak 10 soal terdiri dari lima alternatif pilihan yang dibuat berdasarkan kisi-kisi soal. Soal-soal pre-test dan post-test dikembangkan sendiri oleh guru menggunakan indikator yang sama. Perubahan rata-rata hasil belajar pretest dan post-test yang muncul pada setiap indikator soal akan diperhatikan karena kegiatan pembelajaran yang dilakukan dikatakan berhasil apabila adanya peningkatan hasil belajar setelah diberikan pengajaran dengan multimedia. Adapun langkah-langkah yang akan dilakukan yaitu: perubahan hasil belajar siswa berdasarkan indikator materi, perubahan hasil belajar siswa pada materi teori kinetik gas, dan menentukan perubahan hasil belajar siswa antara sebelum dan setelah pembelajaran dengan menggunakan multimedia digunakan uji McNemar.

\section{Hasil dan Pembahasan}

Kegiatan pembelajaran yang dilakukan untuk melihat peningkatan hasil belajar siswa pada materi teori kinetik gas dengan menggunakan multimedia. Peningkatan hasil belajar ini dapat dilihat dari jumlah siswa yang menjawab benar pada pre-test dan post-test berdasarkan 3 (tiga) indikator materi sesuai kisi-kisi soal.

1. Perubahan Hasil Belajar Siswa Berdasarkan Indikator Materi

Hasil tes yang dilakukan pada sampel penelitian sebanyak 55 orang siswa disajikan dalam Tabel 1.

a. Menganalisis sifat dan hukum gas ideal pada persoalan fisika

$$
\text { Dari sajian rata-rata }
$$

persentase ketiga sekolah, diperoleh peningkatan hasil belajar siswa pada SMA Santo Bonaventura dan MAN Sambas. Tetapi, SMA Negeri 1 Sambas terjadi penurunan. Penurunan ini disebabkan siswa beranggapan soal pre-test dan post-test sama. Secara keseluruhan persentase rata-rata 
ketiga sekolah terjadi peningkatan.

b. Menganalisis hubungan antara tekanan, volum, dan temperatur suatu gas serta merumuskannya dalam suatu persamaan gas umum.
Dari sajian rata-rata persentase ketiga sekolah, diperoleh peningkatan hasil belajar siswa untuk ketiga sekolah. Secara keseluruhan persentase rata-rata ketiga sekolah terjadi peningkatan.

Tabel 1. Persentase hasil belajar pada materi sifat dan hukum gas ideal

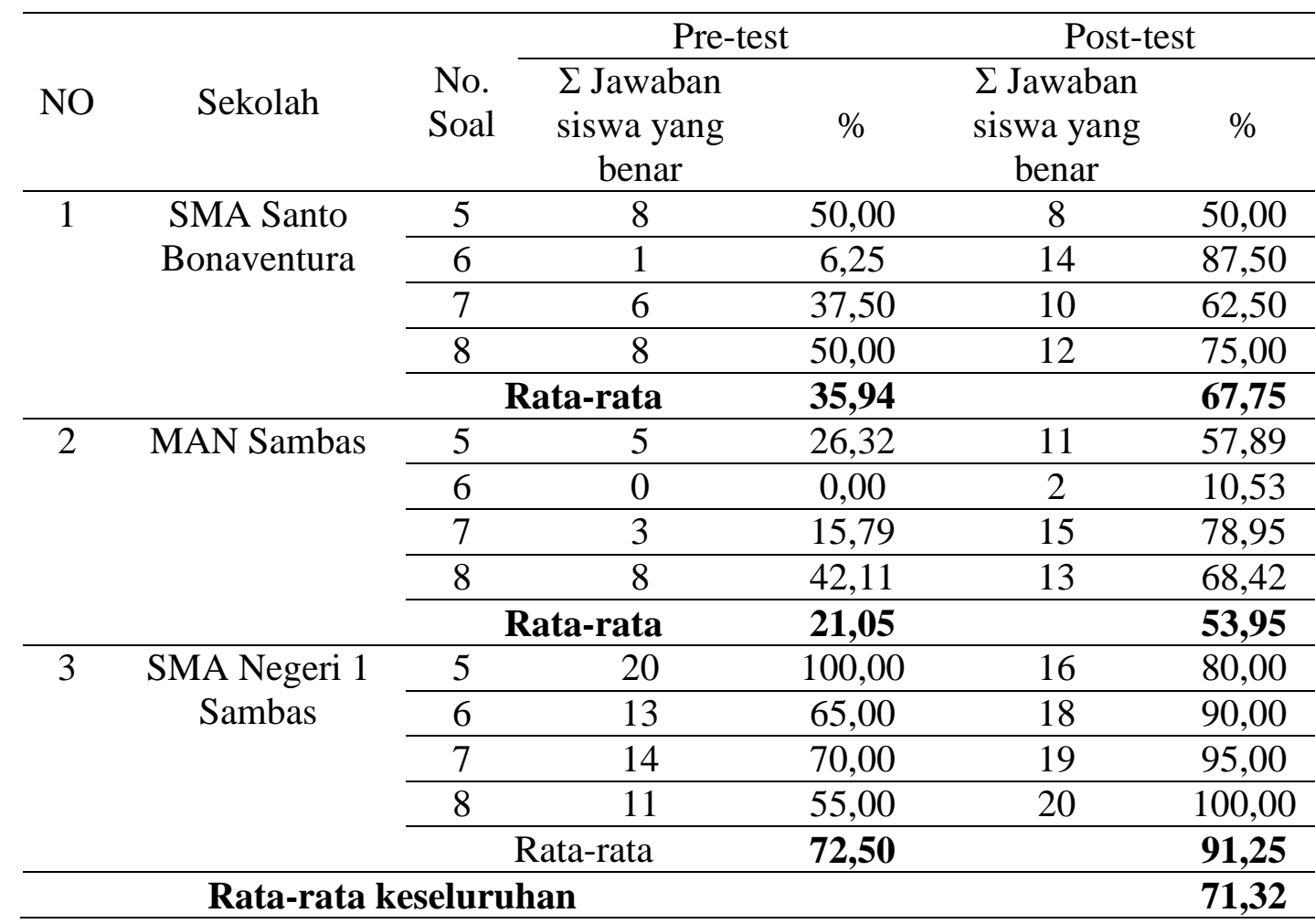

c. Menganalisis energi dalam suatu molekul gas dengan memanfaatkan prinsip ekipartisi energi.

Rata-rata persentase ketiga sekolah, diperoleh peningkatan hasil belajar siswa pada SMA SantoBonaventura dan MAN Sambas (Tabel 3). SMA Negeri 1 Sambas terjadi penurunan disebabkan siswa beranggapan soal pre-test dan post-test sama. Secara keseluruhan persentase rata-rata ketiga sekolah terjadi penurunan.
2. Perubahan Hasil Belajar Belajar siswa pada Materi Teori Kinetik Gas

Berdasarkan perubahan hasil belajar siswa dalam setiap indikator materi, maka dapat dirangkum seperti pada Tabel 4. Dari sajian rata-rata persentase ketiga sekolah, diperoleh peningkatan hasil belajar siswa pada SMA Santo Bonaventura dan MAN Sambas, tetapi SMA Negeri 1 Sambas terjadi penurunan. Penurunan ini disebabkan siswa beranggapan 
soal pre-test dan post-test sama. Secara keseluruhan persentase rata-rata ketiga sekolah terjadi peningkatan.

Tabel 2. Persentase hasil belajar pada materi tekanan, volum, dan temperatur.

\begin{tabular}{|c|c|c|c|c|c|c|}
\hline \multirow[b]{2}{*}{ NO } & \multirow[b]{2}{*}{ Sekolah } & \multirow[b]{2}{*}{$\begin{array}{l}\text { No. } \\
\text { Soal }\end{array}$} & \multicolumn{2}{|c|}{ Pre-test } & \multicolumn{2}{|c|}{ Post-test } \\
\hline & & & $\begin{array}{c}\Sigma \text { Jawaban } \\
\text { siswa yang } \\
\text { benar }\end{array}$ & $\%$ & $\begin{array}{c}\Sigma \text { Jawaban } \\
\text { siswa yang } \\
\text { benar }\end{array}$ & $\%$ \\
\hline \multirow[t]{5}{*}{1} & \multirow{5}{*}{$\begin{array}{l}\text { SMA Santo } \\
\text { Bonaventura }\end{array}$} & 1 & 10 & 62,50 & 9 & 56,25 \\
\hline & & 2 & 2 & 12,50 & 9 & 56,25 \\
\hline & & 3 & 6 & 37,50 & 7 & 43,75 \\
\hline & & 4 & 4 & 25,00 & 7 & 43,75 \\
\hline & & \multicolumn{2}{|c|}{ Rata-rata } & 34,38 & & 50,00 \\
\hline \multirow[t]{5}{*}{2} & \multirow[t]{5}{*}{ MAN Sambas } & 1 & 8 & 42,11 & 14 & 73,68 \\
\hline & & 2 & 4 & 21,05 & 14 & 73,68 \\
\hline & & 3 & 6 & 31,58 & 14 & 73,68 \\
\hline & & 4 & 2 & 10,53 & 17 & 89,47 \\
\hline & & \multicolumn{2}{|c|}{ Rata-rata } & 26,32 & & 77,63 \\
\hline \multirow[t]{6}{*}{3} & \multirow{5}{*}{$\begin{array}{c}\text { SMA Negeri } 1 \\
\text { Sambas }\end{array}$} & 1 & 15 & 75,00 & 15 & 75,00 \\
\hline & & 2 & 19 & 95,00 & 16 & 80,00 \\
\hline & & 3 & 20 & 100,00 & 17 & 85,00 \\
\hline & & 4 & 18 & 90,00 & 19 & 95,00 \\
\hline & & \multirow{2}{*}{\multicolumn{2}{|c|}{$\begin{array}{l}\text { Rata-rata } \\
\text { eluruhan }\end{array}$}} & 90,00 & & 83,75 \\
\hline & Rata-rata & & & 50,23 & & 70,46 \\
\hline
\end{tabular}

Tabel 3. Persentase energi dalam dan ekipartisi energi

\begin{tabular}{|c|c|c|c|c|c|c|}
\hline \multirow[b]{2}{*}{$\mathrm{NO}$} & \multirow[b]{2}{*}{ Sekolah } & \multirow[b]{2}{*}{ No soal } & \multicolumn{2}{|c|}{ Pre-test } & \multicolumn{2}{|c|}{ Post-test } \\
\hline & & & $\begin{array}{c} \\
\text { jawaban } \\
\text { siswa } \\
\text { yang } \\
\text { benar } \\
\end{array}$ & $\%$ & $\begin{array}{c}\Sigma \\
\text { jawaban } \\
\text { siswa } \\
\text { yang } \\
\text { benar } \\
\end{array}$ & $\%$ \\
\hline \multirow[t]{3}{*}{1} & SMA Santo & 9 & 6 & 37,50 & 9 & 56,25 \\
\hline & Bonaventura & 10 & 10 & 62,50 & 15 & 93,75 \\
\hline & & \multicolumn{2}{|c|}{ Rata-rata } & 50,00 & & $\overline{75,00}$ \\
\hline \multirow[t]{3}{*}{2} & MAN Sambas & 9 & 11 & 57,89 & 9 & 47,37 \\
\hline & & 10 & 11 & 57,89 & 18 & 94,74 \\
\hline & & \multicolumn{2}{|c|}{ Rata-rata } & 57,89 & & 71,05 \\
\hline \multirow[t]{4}{*}{3} & SMA Negeri 1 & 9 & 18 & 90,00 & 15 & 75,00 \\
\hline & Sambas & 10 & 20 & 100,00 & 5 & 25,00 \\
\hline & & \multicolumn{2}{|c|}{ Rata-rata } & 95,00 & & 50,00 \\
\hline & Rata-rata 1 & luruhan & & 67,63 & & 65,35 \\
\hline
\end{tabular}


Tabel 4. Perubahan persentase hasil belajar siswa.

\begin{tabular}{ccccc}
\hline NO & Sekolah & $\begin{array}{c}\text { Rata-rata } \\
\text { persentase pre- } \\
\text { test }\end{array}$ & $\begin{array}{c}\text { Rata-rata } \\
\text { persentase post- } \\
\text { test }\end{array}$ & Peningkatan \\
\hline 1 & $\begin{array}{c}\text { SMA Santo } \\
\text { Bonaventura }\end{array}$ & 40,10 & 64,58 & 24,48 \\
\hline 2 & MAN Sambas & 35,09 & 67,54 & 32,46 \\
\hline 3 & SMA Negeri 1 Sambas & 85,83 & 75,00 & $-10,83$ \\
\hline \multicolumn{2}{c}{ Rata-rata Keseluruhan } & $\mathbf{5 3 , 6 8}$ & $\mathbf{6 9 , 0 4}$ & $\mathbf{1 5 , 3 7}$ \\
\hline
\end{tabular}

Dalam penelitian ini ditemukan perubahan hasil belajar siswa setelah diberikan pembelajaran menggunakan multimedia pada materi teori kinetik gas. Hasil analisis yang berdasarkan indikator materi menganalisis sifat dan hukum gas ideal pada persoalan fisika terjadi peningkatan pada SMA Santo Bonaventura $(15,63 \%)$ dan MAN Sambas $\quad(51,32 \%), \quad$ sedangkan SMANegeri 1 Sambas terjadi penurunan $6,25 \%$ karena siswa kurang teliti dalam menjawab soal post-test. Sebagian siswa beranggapan soal pre-test dan posttest sama, sehingga siswa keliru dalam menyelesaikan soal post-test. Indikator materi menganalisis hubungan antara tekanan, volum, dan temperatur suatu gas serta merumuskannya dalam suatu persamaan gas umum terjadi peningkatan hasil belajar siswa untuk ketiga sekolah, yaitu: SMA Santo Bonaventura (32,81\%), MAN Sambas $(32,89 \%)$, dan SMA Negeri 1 Sambas $(18,75 \%)$.

Penurunan hasil belajar siswa $45,00 \%$ pada SMA Negeri 1 Sambas ditemukan kembali dalam menyelesaikan soal pada indikator materi menganalisis energi dalam suatu molekul gas dengan memanfaatkan prinsip ekipartisi energi. Tetapi berbeda dengan SMA Santo Bonaventura $(25,00 \%)$, dan MAN Sambas $(13,16 \%)$ mengalami peningkatan. Secara keseluruhan pembelajaran mengggunakan multimedia yang diterapkan pada ketiga sekolah khususnya pada materi Teori Kinetik Gas dapat meningkatkan hasil belajar siswa $(15,37 \%)$. SMA Santo Bonaventura Sambasmeningkat $24,48 \%$, MAN Sambas 32,46\%, dan SMA Negeri 1 Sambas menurun 10,83\%. Walaupun ada beberapa kendala yang ditemukan sewaktu melakukan penelitian. Sebagian siswa tidak berkonsentrasi penuh pada saat berlangsungnya pembelajaran karena kegiatan pembelajaran dilakukan setelah ulangan semester genap.

Menurut Rosalin (2008), media pengajaran dapat mempertinggi proses siswa dalam pengajaran yang pada gilirannya diharapkan dapat mempertinggi hasil belajar yang dicapainya. Sebab, dalam media pengajaran hal-hal yang abstrak dapat dikonkritkan dan halhal yang kompleks dapat disederhanakan. Materi teori kinetik gas yang bersifat abstrak menjadi konkrit melalui animasi pergerakan partikel-partikel gas. Uji statistik McNemar digunakan untuk melihat perubahan hasil belajar siswa dengan 
hipotesis, Ho : rata-rata hasil belajar posttest dan rata-rata hasil belajar pretest tidak ada perbedaan, sedangkan Ha :. rata-rata hasil belajar posttest dan rata-rata hasil belajar pretest ada perbedaan. Hasil perhitungan diperoeh bahwa $\mathrm{X}_{\text {hitung }}^{2}$ rata-rata $=9,10$ dan $\mathrm{X}_{\text {tabel }}^{2}$ ratarata $=3,84$ ini berarti bahwa Ho ditolak dan $\mathrm{Ha}$ diterima dimana, $\mathrm{X}_{\text {hitung }}^{2}>\mathrm{X}_{\text {tabel, }}^{2}$ artinya terjadi peningkatan hasil belajar siswa pada materi teori kinetik gas menggunakan multimedia.

\section{Simpulan dan Saran}

Berdasarkan analisis data dan pembahasan dapat disimpulkan bahwa: (a) secara keseluruhan, ratarata persentase dalam mengerjakan soal-soal pre-test tentang Teori Kinetik Gas sebesar 53,68 \% dari 55 siswa. Sedangkan rata-rata persentase post-test $69,04 \%$ dari 55 siswa. Peningkatan rata-rata persentase hasil belajar siswa pada materi Teori Kinetik Gas menggunakan multimedia sebesar $15,37 \%$, (b) hasil perhitungan dengan menggunakan uji McNemar, dari jumlah keseluruhan sepuluh soal terjadi peningkatan hasil belajar siswa terhadap materi Teori Kinetik Gas antara sebelum dan sesudah pembelajaran menggunakan multimedia, dimana $X^{2}{ }_{\text {hitung }}$ rata-rata $=$ 9,10 dan $X^{2}{ }_{\text {tabel }}$ rata-rata $=3,84$ dengan $X_{\text {hitung }}^{2}>X^{2}$ tabel.

Berdasarkan hasil penelitian guru hendaknya mempertimbangkan pengajaran dengan menggunakan multimedia untuk mempermudah siswa memahami konsep teori kinetik gas. Penelitian hasil belajar siswa agar dilanjutkan baik tentang materi lain atau menggunakan metode yang lain.

\section{DaftarPustaka}

Anonimous. 2011. Desain Program Remedial dan Pengayaan Artikel Baru simpel PAS.http://simpelpas.wordpress. com/2011/06/08/desainprogram-perbaikan-danpengayaan-artikel-baru-simpelpas/ Diakses pada tanggal 24 Juni 2011.

Ischak dan Warji. 1987. Program Remedial Dalam Proses Belajar Mengajar Yogyakarta: Liberty.

Rosalin, Elin. 2008. Bagaimana Menjadi Guru Inspiratif. Bandung : PT. Karsa Mandiri Persada.

Simpson Ronald D, dan Norman D Anderson. 1981. Science, Students, and Schools John Wiley \& Sons United State of America (New York).

Sumadi, Suryabrata 2005 Metodologi Penelitian. Yogyakarta: Rajawali Pers.

Supiyanto. 2003. Fisika Untuk SMU Kelas 3. Jakarta: Erlangga.

Wikipedia. 2011. Microsoft PowerPoint.

http://id.wikipedia.org/wiki/Mic rosoft_ PowerPoint Diakses pada tanggal 24 Juni 2011. 